\title{
Essencialidade da educação presencial na emergência da COVID-19 no Brasil: análise do Projeto de Lei no 5.595/2020
}

\author{
The essential role of in-person schooling in Brazil \\ during the COVID-19 emergency: analysis of Bill \\ of Law n. 5,595/2020
}

\author{
Esencialidad de la educación presencial en el \\ surgimiento del COVID-19: análisis del Proyecto \\ de Ley n. 5.595/2020
}

\author{
Lenir Nascimento da Silva 1 \\ Márcia Denise Pletsch 2 \\ Francine de Souza Dias 1
}

doi: 10.1590/0102-311X00107321

Em janeiro de 2020, a Organização Mundial da Saúde (OMS) declarou a epidemia de COVID-19 uma Emergência de Saúde Pública de Importância Internacional (ESPII). Atualmente, o Brasil enfrenta uma grave crise social com índices de desemprego nunca vistos no país 1 , impactos econômicos, políticos e científicos imensuráveis diante das milhares de vidas perdidas.

As desigualdades sociais e educacionais têm se ampliado, provocando uma crise sem precedentes do sistema educacional público. Há mais de um ano, a maioria das crianças e dos jovens estão sem aulas presenciais ou têm aulas remotas, com enormes prejuízos para o seu desenvolvimento, em decorrência da precariedade de acesso aos recursos tecnológicos e à Internet 2 .

Além disso, muitas famílias estão impossibilitadas de assistirem as crianças durante o ensino remoto em virtude de acúmulo de atividades, busca por formas de sobrevivência e baixos níveis de escolaridade. Diante desse quadro, é fundamental o reconhecimento dos marcadores de território, classe, gênero e raça nesse debate. A perspectiva inclusiva da educação é outro elemento ofuscado no panorama de crise sanitária. Consequentemente, necessidades sociais e educacionais das pessoas com deficiência frequentemente ficam invisibilizadas nas discussões.

Partindo desse cenário, discutimos o Projeto de Lei no 5.595/2020 (PL) 3, que "Dispõe sobre o reconhecimento da Educação Básica e de Ensino Superior, em formato presencial, como serviços e atividades essenciais", aprovado na Câmara dos Deputados, em abril de 2021. Trata-se de um artigo sobre um tema conjuntural e premente, produzido por mulheres implicadas com a educação, com a saúde coletiva e, sobretudo, com o direito à vida.

O PL impõe a interdição da "suspensão das atividades educacionais em formato presencial" 3, na rede pública e privada, mesmo em períodos de calamidade e de emergências sanitárias. Uma tentativa de resolver a questão do fechamento das escolas, que desconsidera a multidimensionalidade do problema, as regulamentações existentes 4 e os diversos atores envolvidos com a discussão ${ }^{5}$. A determinação se apoia na certeza da "essencialidade dos serviços educacionais" 3 , principal enunciado do documento. Que discursos, valores e técnicas sustentam a proposta? Quais as suas implicações?

É indiscutível que a educação é um valor para a sociedade e um direito constitucional. Também é inegável que a educação é um dos setores mais impactados pela pandemia de COVID-19, demandando esforços que garantam a promoção do direito. Porém, diferente do valor do direito a ela, os modos
1 Escola Nacional de Saúde Pública Sergio Arouca, Fundação Oswaldo Cruz Rio de Janeiro, Brasil. 2 Universidade Federal Rural do Rio de Janeiro, Nova Iguaçu, Brasil.

Correspondência L. N. Silva

Escola Nacional de Saúde Pública Sergio Arouca, Fundação Oswaldo Cruz. Rua Leopoldo Bulhões 1480, Rio de Janeiro, RJ 21041-210, Brasil.

lenircmj@gmail.com 
de promoção da educação precisam ser discutidos, uma vez que, em cenários de grave ameaça sanitária, a vida é o maior valor. A preservação da vida impõe que questionemos certezas e consideremos as múltiplas dimensões dos problemas, pois existem muitos perigos na existência de uma única história, como nos adverte Chimamanda Adichie 6.

O texto do PL ressalta a garantia da educação como direito social, um dever do Estado e da família, que precisa ser provido em "igualdade de condições para o acesso e permanência na escola" 3 . Assim, a educação é considerada um dispositivo essencial para "amenizar as desigualdades sociais" 3.

O projeto sublinha o papel fundamental da educação para o desenvolvimento econômico e social do país. Além disso, aponta a progressão lenta da educação no Brasil, em razão do número de crianças fora da escola 3. Para que a argumentação ganhe potência retórica, o texto evoca a linguagem do planejamento, reduzindo a educação aos sentidos do serviço e da atividade 3 , e evidencia a consideração valorativa sobre a insuficiência do trabalho dos governantes locais, pois esses conceituam a educação como uma atividade primordial e não essencial. Com isso, o PL desmerece a importância das decisões regionais e locais ao mesmo tempo em que desconsidera os riscos de sua possível aprovação.

Ainda sob a retórica do desenvolvimento, o Brasil é colocado em posição de defasagem em relação a outros países do mundo, em função do número de dias sem aulas presenciais e da falta de efetividade para garantir seu retorno. A ideia de despreparo do Poder Público para assegurar educação remota constrói a perspectiva de que as escolas não deveriam ficar fechadas por tanto tempo. $\mathrm{O}$ discurso futurista de que as soluções paliativas significarão um real atraso para o progresso educacional produz a perspectiva de "tempo perdido" para o desenvolvimento do país 3 .

Ao promover a educação por meio do enunciado do direito, o PL ofusca outros aspectos referentes ao fechamento das escolas durante a atual emergência sanitária. A construção invisibiliza a relação de interdependência entre os setores como elemento fundamental para a adequada promoção dos preceitos da Carta Magna, constituindo um discurso falacioso sobre o direito à educação. Tal jogo narrativo associa a ideia de acesso ao sentido da essencialidade da educação e a concepção de proteção social à prática da permanência. Ao fazê-lo, desconsidera que fechamento e reabertura podem igualmente produzir iniquidades. $\mathrm{O}$ afastamento social aumentou os riscos de violência, insegurança alimentar e alterações da saúde mental, ampliando as disparidades existentes 7 . A experiência de outros países mostra que a reabertura segura foi possível com a associação de medidas de mitigação, mudanças na estrutura das escolas e ações contínuas de vigilância 7,8,9. Porém, a reabertura no Brasil pode infligir maiores riscos à vida das pessoas mais vulneráveis, devido às diferenças entre escolas públicas e privadas 5,10 e às dificuldades enfrentadas pela vigilância em saúde.

A produção de sentido do PL é contraditória e ameniza o contexto sanitário crítico em que foram decretados os fechamentos das escolas - um grave cenário, não um problema momentâneo, conforme faz crer seu texto ${ }^{3}$. Dados epidemiológicos nacionais e internacionais mostram que a maior parte das regiões do mundo relatou declínio no número de mortes em julho de 2021. Porém, o Brasil foi o país que mais notificou casos novos de óbito ${ }^{11}$. Além disso, os casos graves de COVID-19 em criança são raros, mas acontecem 12

O jogo discursivo do texto suprime as tentativas de proteção à vida contidas nas medidas de distanciamento social, que visam garantir: "leitos, respiradores, equipamentos de proteção individual e profissionais em número suficiente para absorver o aumento de demanda" 13, além de "acesso e atendimento aos casos de COVID-19" 13, sem descontinuidade de serviços de saúde. Ao fazer isso, o documento também enuncia as existências com menos valia, pois, na ausência das medidas de proteção e de assistência à saúde para salvar vidas, aquelas que se perdem são marcadas por cor, classe e funcionalidade.

A OMS determina que, na situação de transmissão comunitária, a abordagem deve ser baseada no risco e em medidas de saúde pública para garantir a continuidade da educação das crianças 14. A organização considera que seja necessária uma ampla variedade de providências em áreas com tendências crescentes de casos, hospitalizações e mortes por COVID-19, incluindo o fechamento de escolas 14 . Porém, ao universalizar a determinação de abertura das unidades de educação, o PL não somente ignora a validade das orientações da OMS, mas também tensiona as diretrizes da política de saúde no Brasil. Nessa lógica, o documento legal não deixa claro que medidas de segurança garantiriam o funcionamento ininterrupto das escolas. Ademais, o que fez o Poder Público para amenizar os impactos da pandemia na educação pública nacional? 
Segundo dados da imprensa 15 , até março de 2021, nenhum estado havia comprado equipamentos digitais para o ensino remoto. Além disso, o Ministério da Educação teve o menor gasto em uma década, fazendo cortes substanciais no orçamento para 2021.

O discurso do PL valoriza o desenvolvimento e o papel da educação para promovê-lo. Nesse sentido, crianças e jovens que permanecem fora da escola constituem um obstáculo. Outrossim, o fechamento das escolas por longo tempo acontece, segundo o documento, por ineficiência do Poder Público e dos governantes locais ${ }^{3}$. A ideia de tempo perdido está conectada a uma prospecção de continuidade do desenvolvimento e ao governo da infância. Ao deslocar o sentido da educação da condição de primordial para essencial, o documento assegura potência retórica, promove sua aceitação, porém não constrói condições para sua aplicação no cenário de pandemia.

O processo de aprovação na Câmara dos Deputados evidencia a importância dos auditórios oportunos para concretização de metas políticas 16 . A sagacidade da argumentação do projeto reside na capacidade de produção de juízo de valor específico e na promoção da adesão. Para constituir adesão, os valores subjacentes da produção discursiva devem ser aceitos nas realidades a que se destinam e precisam fazer parte delas 16 . Adesão, auditório qualificado e juízo de valor - essa tripla intercessão organiza a retórica estabelecida no PL como técnica de persuasão. Segundo Adichie 6 (p. 12), "o poder é a habilidade não apenas de contar a história de outra pessoa, mas de fazer que ela seja sua história definitiva”, ou seja, governá-la.

O discurso de proteção da infância, que sustenta a promoção do direito à educação no PL, e o enunciado do tempo perdido, que elenca suas técnicas de persuasão, constituem-se em verdadeiros dispositivos de governo da vida das pessoas ${ }^{17}$. O processo de construção do sentido da essencialidade da educação, para que seja compulsório o formato presencial das atividades educacionais, exclui dimensões imprescindíveis do problema de quando e como reabrir as escolas, que precisam fazer parte de uma ampla discussão: insuficiência das medidas e políticas de proteção social; insuficiência de vacinas para a população; vacinação de crianças; saúde mental de crianças e profissionais da educação; transporte público e congelamento dos orçamentos das políticas públicas.

Ressaltamos também o fato de que o discurso da essencialidade da educação em formato presencial se apoia na própria desproteção social produzida pelo Estado. Sua produção vai ao encontro das demandas das pessoas com maiores necessidades materiais e, portanto, alcança o apoio das populações mais vulnerabilizadas frente à pandemia - outra forma de produzir valores e adesão. Isso ocorre no cenário de precária promoção do direito constitucional à assistência social.

O retorno às aulas presenciais é urgente, mas precisa ser discutido em fóruns ampliados, à luz da situação epidemiológica local, fundamentado em evidências, baseado na diversidade de experiências, na perspectiva da complexidade e impõe mudanças difíceis de serem alcançadas em curto prazo 5. Dessa forma, considerando a importância central das instituições de educação, posicionamo-nos contra a universalização promovida pelo PL e convocamos a sociedade para discutir a volta das atividades educacionais em uma perspectiva que compreenda os diversos setores implicados. Dado o dramático cenário epidemiológico atual 11,12, a promoção da educação em conformidade com o PL produzirá não somente contradições e incertezas, mas, sobretudo, uma grave ameaça à vida. Uma perigosa história única que precisa ser debatida amplamente e refutada.

\section{Colaboradores}

L. N. Silva, M. D. Pletsch e F. S. Dias participaram de todas as etapas de produção do artigo.

\section{Informações adicionais}

ORCID: Lenir Nascimento da Silva (0000-00029483-2873); Márcia Denise Pletsch (0000-00015906-0487); Francine de Souza Dias (0000-00015621-1796). 


\section{Referências}

1. Instituto Brasileiro de Geografia e Estatística. Desemprego. https://www.ibge.gov.br/ex plica/desemprego.php (acessado em 23/Abr/ 2021).

2. United Nations Educational, Scientific and Cultural Organization. Global monitoring of school closures. https://pt.unesco.org/ covid19/educationresponse (acessado em 23/ Abr/2021).

3. Câmara dos Deputados. Projeto de Lei no 5.595, de 21 abril de 2020. Dispõe sobre o reconhecimento da Educação Básica e de Ensino Superior, em formato presencial, como serviços e atividades essenciais. https://www. camara.leg.br/proposicoesWeb/prop_mos trarintegra? codteor $=1954422 \&$ filename $=$ $\mathrm{PL}+5595 / 2020$ (acessado em 23/Abr/2021).

4. Conselho Nacional de Educação. Resolução CNE/CP no 2, de 10 de dezembro de 2020. Institui Diretrizes Nacionais orientadoras para a implementação dos dispositivos da Lei no 14.040 , de 18 de agosto de 2020, que estabelece normas educacionais excepcionais a serem adotadas pelos sistemas de ensino, instituições e redes escolares, públicas, privadas, comunitárias e confessionais, durante o estado de calamidade reconhecido pelo Decreto Legislativo no 6, de 20 de março de 2020. Diário Oficial da União 2020; $11 \mathrm{dez}$.

5. Curi LRL, Castro MHG, Pacios A, Silveira A, Ramos MN, Menezes S, et al. Diretrizes nacionais para o retorno às aulas presenciais e reorganização do calendário escolar. https:// www.fucap.edu.br/wp/diretrizes-nacionaispara-o-retorno-as-aulas-presenciais-e-reor ganizacao-do-calendario-escolar/ (acessado em 12/Jul/2021).

6. Adiche $\mathrm{CN}$. O perigo de uma história única. Rio de Janeiro: Companhia das Letras; 2009.

7. Rajapakse N, Dixit D. Human and novel coronavirus infections in children: a review. Paediatr Int Child Health 2021; 41:36-55.

8. Suk JE, Vardavas C, Nikitara K, Phalkey R, Leonardi-Bee J, Pharris A, et al. The role of children in the transmission chain of SARSCoV-2: a systematic review and update of current evidence. medRxiv 2020; 9 nov. https:// www.medrxiv.org/content/10.1101/2020.11. $06.20227264 \mathrm{v} 1$.
9. Xu W, Li X, Dozier M, He Y, Kirolos A, Lang $\mathrm{Z}$. What is the evidence for transmission of COVID-19 by children in schools? A living systematic review. J Glob Health 2020; 10:021104.

10. Pronko M. Educação pública em tempos de pandemia. In: Silva LB, Dantas AV, organizadores. Crise e pandemia: quando a exceção é regra geral. Rio de Janeiro: Escola Politécnica de Saúde Joaquim Venâncio, Fundação Oswaldo Cruz; 2020. p. 113-29.

11. World Health Organization. COVID-19 Weekly Epidemiological Update: data as received by WHO from national authorities, as of 27 June 2021. https://www.who.int/docs/ default-source/coronaviruse/situation-re ports/20210629_weekly_epi_update_46.pdf (acessado em 12/Jul/2021).

12. Secretaria de Vigilância em Saúde, Ministério da Saúde. COVID-19. Boletim Epidemiológico 2021; 68(24). https://www.gov.br/saude/ pt-br/media/pdf/2021/junho/25/68_bole tim_epidemiologico_covid.pdf.

13. Secretaria de Vigilância em Saúde, Ministério da Saúde. COVID-19. Boletim Epidemiológico 2020; 8(15). http://www.cofen.gov.br/ wp-content/uploads/2020/04/be-covid08-final.pdf.pdf.

14. World Health Organization. Considerations for school-related public health measures in the context of COVID-19. https://www.who. int/publications/i/item/considerations-forschool-related-public-health-measuresin-the-context-of-covid-19 (acessado em 23/ Abr/2021).

15. Alfano B. Um ano após escolas fecharem, nenhum estado comprou equipamentos digitais para ensino remoto. Jornal Extra 2021; 15 mar. https://extra.globo.com/noticias/educacao/ um-ano-apos-escolas-fecharem-nenhumestado-comprou-equipamentos-digitais-paraensino-remoto-24924685.html.

16. Perelman C. Retóricas. São Paulo: Martins Fontes; 2004.

17. Foucault M. Microfísica do poder. São Paulo: Graal; 2008
Recebido em 27/Abr/2021

Versão final reapresentada em 15/Jul/2021

Aprovado em 16/Jul/2021 